\title{
A Pragmatic, Step-by-Step Guide for Qualitative Methods: Capturing the Disaster and Long-Term Recovery Stories of Katrina and Rita
}

Loren D. Marks

Brigham Young University - Provo, loren_marks@byu.edu

Follow this and additional works at: https://scholarsarchive.byu.edu/facpub

Part of the Other Social and Behavioral Sciences Commons

\section{Original Publication Citation}

Marks, L. (2015). A pragmatic, step-by-step guide for qualitative methods: Capturing the disaster and long-term recovery stories of Katrina and Rita. Current Psychology, 34, 494-505.

\section{BYU ScholarsArchive Citation}

Marks, Loren D., "A Pragmatic, Step-by-Step Guide for Qualitative Methods: Capturing the Disaster and Long-Term Recovery Stories of Katrina and Rita" (2015). Faculty Publications. 4861.

https://scholarsarchive.byu.edu/facpub/4861 


\title{
A Pragmatic, Step-by-Step Guide for Qualitative Methods: Capturing the Disaster and Long-Term Recovery Stories of Katrina and Rita
}

\author{
Loren D. Marks ${ }^{1}$
}

Published online: 10 June 2015

(C) Springer Science+Business Media New York 2015

\begin{abstract}
This paper commences with candid warnings about the difficulties of publishing and funding qualitative research along with a brief discussion regarding why these difficulties persist. The paper then provides a methodological tour of the qualitative portion of the Louisiana Healthy Aging Study (LHAS), a mixed-method study of psychological health, coping, and adjustment during the immediate and longer term aftermath of the 2005 Hurricanes Katrina and Rita. Next, I provide a proven, pragmatic guide to navigate through a qualitative research project from development to completion. A guide for doing solo qualitative ("monk/nun in a cell") work is provided (Table 1) but the article focuses on the Four-Phase, Team-Based (or "Quad-Squad") Method. This method, originally designed for solo researchers, has been adapted for teambased application (including the extensive utilization of undergraduate and graduate students). The method is presented as a pragmatic and productive approach to publishing more valid, reliable, and rigorous qualitative research.
\end{abstract}

Keywords Qualitative $\cdot$ Method $\cdot$ Disasters $\cdot$ Katrina . Coding $\cdot$ Team

This paper provides a methodological tour of the qualitative portion of the Louisiana Healthy Aging Study (LHAS), a mixed-method study that has, for the past decade, examined psychological health, coping, and adjust-

Loren D. Marks

loren_marks@byu.edu

School of Family Life, Brigham Young University, Provo, UT, USA ment during the immediate and long-term aftermath of Hurricanes Katrina and Rita. The article also provides a proven, pragmatic guide to navigate through a qualitative research project from development to completion. This approach, originally designed for solo researchers, has been adapted for team-based application (including the extensive utilization of undergraduate and graduate students). The individual-level and team-based approaches are both provided and explained. My tone and approach during the article will be conversational.

My objective in this paper (based on a decade of trial, error, and refining) is to provide a template for prospective qualitative researchers who are determined to pursue a qualitative course in their work. First, however, let me be direct. If you are a scholar or aspiring scholar in the social, human, and/or behavioral sciences and you are not yet tenured, qualitative methods are a dangerous dark art in which to dabble. Elsewhere, I have offered four explanations and supports for this statement that may justly be described as warnings. These include: Warning 1 - Doing Qualitative Research Well is Time Intensive; Warning 2 - Qualitative Research is Difficult to Publish; Warning 3 - It is Exceptionally Difficult to Obtain External Funding for Qualitative Research; and Warning 4 - It is Difficult to Land an Initial Job as a Qualitative Researcher. Although space does not permit an in-depth review of each of these dangers here, they are real. ${ }^{1}$

\section{What Underlies These Challenges?}

The reasons underlying the pronounced challenges of publishing and/or funding qualitative research are many

\footnotetext{
${ }^{1}$ For example, a dated but systematic study of one leading journal indicated that less than $2 \%$ of all published articles over a five-year span were qualitative (Ambert et al. 1995).
} 
and mutually reinforcing. However, one overarching challenge is that there is still a pervasive lack of respect for qualitative research methods amongst many (perhaps most) senior social scientists. As a concrete and specific case in point, we will consider an excerpt from a blind review of a qualitative piece I submitted in 2002 to a psychology journal that had not published a qualitative article in the preceding 4 years. $^{2}$ A portion of the review from "Reviewer B" stated:

Whatever this [qualitative] paper has to offer, I, for one, remain to be convinced that the journal to which it has been submitted is the appropriate publication outlet for it.... The issue I will raise is by no means restricted to this paper, but to the entire approach to inquiry manifested in this paper. There are certainly many ways of knowing; scientific knowing is only one of them. But what defines it, and I say this because I envision this journal (and others like it) as a journal of science rather than of phenomenology, hermeneutics, or the like, is the employment of a replicable method of inquiry which thereby allows others to seek to replicate findings reported to ensure that they are indeed reliable. In consequence, I do not see the work being reported here as scientific in the least. And I readily admit to - indeed embrace with religious fervor-the bias I am proclaiming. To me, the core question becomes, what makes this work distinct from journalism? Until that can be answered to my satisfaction, I prefer to gather information of the kind presented in this paper in newspapers and magazines, where the journalism is transparent. What is being reported here may be "research," but it does not come close to representing scientific "research" nor providing anything close to "scientific evidence." ...I do not think it belongs in this journal.

Although I must confess that this review stung initially, I have read it several times with benefit. I remain grateful for Reviewer B's honesty and transparency, as well as his clarity in articulating a core question that qualitative researchers need to address-first to themselves and then to their readers: "Is your research method 'science' and if so, why?" Additional respect for qualitative research is more likely to be forthcoming if we who employ qualitative methodologies can satisfactorily respond to this central question. It is unlikely that "Reviewer B" (who "embrace[s] with religious fervor-

\footnotetext{
${ }^{2}$ Submitting to a journal with this record is not wise if publication is your goal. Young bulls sometimes take a headlong run at a fencepost to test for firmness. I found this particular post to be quite solid.
}

the bias [he/she is] proclaiming") will be significantly swayed, ${ }^{3}$ but let us not forget Reviewers A and C. Those two reviewers are briefly addressed next.

\section{Pragmatism and Peer-Reviewed Publishing: A Note on Reviewers $A$ and $C$}

Let us focus on the pragmatics of the peer-reviewed publishing of qualitative research for a moment. Based on: (1) a personal sample of about 100 qualitative submissions or resubmissions over the years, ${ }^{4}$ and (2) conversations with other social scientists with similar levels of qualitative research activity, I offer the following synopsis of collective experience. A threereviewer "draw" from a mainstream social science journal will often include: (a) one reviewer who is open to (perhaps even favorably disposed towards) qualitative research - we will call this individual Reviewer A; (b) one reviewer who holds antiqualitative, Reviewer B-type biases; and (c) a third reviewer who is ambivalent, lukewarm, or skeptical about qualitative methods (Reviewer C). Regardless of the topic, focus, or potential contribution of the piece itself, an essential task in this recurring test case is the challenge to win over Reviewer C. This smaller victory is imperative to have a viable chance for a favorable publication decision by the editor. I would estimate my publication success rate for solo-authored, qualitative pieces at perhaps one out of three submissions. Some qualitative researchers fare better, some fare worse, but either way, many have abbreviated research careers. I was well aware of these challenges when I was contacted by Professor Katie Cherry not long after Hurricanes Katrina and Rita struck the Gulf Coast in August and September of 2005.

\section{An Introduction to the LHAS Project}

When I first met Professor Katie Cherry in 2005, she was already a prolific social scientist and her research, her publications, and her scientific worldview were almost solely positivist and quantitative. I was subsequently struck by her desire to move onto novel ground and to include a substantial qualitative component in the (then) recently funded Louisiana

\footnotetext{
${ }_{3}^{3}$ If a lack of respect from many Reviewer $B$ types within the field is one reason that qualitative researchers are often unrepresented in leading journals and on grantors' A-lists, a second prevalent factor may be that much extant qualitative research does not command respect. In short, I believe that while some increased respectability has and will come through philosophical discussion and reconsideration (i.e., Slife and Williams 1995), the proof is ultimately in the research-based pudding. Increased respect for the method will come when the caliber of published qualitative work increases.

${ }^{4}$ This figure includes successful, pending, and unsuccessful experiences. As noted, the latter classification of "unsuccessful" submissions is the most typical.
} 
Table 1 The Quad-Squad Approach to Qualitative Research

Phase One: Developing the Interview Protocol and Defining the Sample

1 - Select research topic.

2 - Conduct an EXTENSIVE Review of Literature

3 - From the Lit Review, notice not only what is known but what is NOT known

4 - Formulate 1-3 fascinating WHY, HOW, or PROCESS related research questions

5 - Develop your questionnaire with sensitivity to your review of literature, your research questions, and real people in the real world.

6 - Submit project and questions to the Institutional Review Board (IRB)

7 - Subject your Interview Questionnaire to the scrutiny of peers AND laypersons

8 - Make changes to Interview Questionnaire as needed (no more than 20 questions).

9 - Determine the purposive/prototypical sample for your study.

\section{Phase Two: Data Collection and Coding}

1 - Conduct a couple of pilot interviews (Use two digital recorders). NOTE: Select an interviewer that participants will trust with their truth.

2 - Make additional adjustments to the Interview Questionnaire, if needed

3 - Begin interviewing your purposive/prototypical sample

4 - Immediately following each interview, write field notes to yourself. Describe overall impressions, non-verbal communication, thoughts, and connections that ran through your mind-as well as potential follow-up questions.

5 - (In solo work) Transcribe the interviews yourself as soon as they have been conducted. Doing so gives you multiple exposure before you begin coding.

6 - Begin Open Coding ASAP after first interview(s) (Intra-Interview Only).

7 - Continue to conduct interviews. (Scrutinize interviewer probes and style on the audio and transcripts to help improve interviews as the project progresses.)

8 - Do a Numeric Content Analysis (NCA) of the Open Coding Concepts in each interview. Namely, what concepts occurred and how many times were they mentioned in each interview?... (Post-It notes recommended; make certain to write the identification information/number from interview on each NCA).

9 - Following the NCA for each interview, scrutinize the Post-It to see if there is a concept that is inadequately represented by NCA alone (e.g., they may only have mentioned a concept one time, but the concept was salient.)

10 - After 4-6 interviews have been Open Coded, begin comparing codes and NCAs across interviews.

11 - Place all NCAs (Post-Its) on a sheet or two of paper, photocopy, and return the NCAs to their native interview

12 - Use the photocopied sheet as your "at-a-glance" across-interview coding tool allowing you to see the NCAs for all individual interviews. This sheet will present a picture of the project as a composite.

13 - Narrow all presented concepts from interviews down to the top fifteen or so.

14 - Examine remaining concepts and begin to eliminate pretenders (i.e., concepts that may seem important at first, but are not supported across interviews) from contenders (i.e., salient and frequent concepts that do emerge across interviews).

15 - Consider combining two or more similar concepts to form a theme: (e.g., "coping," "loss," and "hard times" may = "Coping with Life's Challenges."

16 - Continue to conduct interviews, performing open coding as soon as possible.

17 - Using NCAs, systematically identify 4-6 core themes that emerge from the data.

18 - Confirm/Challenge these themes as you continue so that you have a high level of confidence that you are capturing the core themes. If the project is solo, have an additional coder or two double-check your work. If the project is using a team-based, Quad-Squad approach, all core themes should be identified by consensus.

Phase Three: Caching the Rocks and Gems for each Theme

1 - You now have your 4-6 "grounded" core themes that you have systematically derived through a process of open coding, numerical content analysis (NCA), across-interview coding, and combination/elimination of themes.

2 - In connection with each of the 4-6 themes (e.g., "Coping with Life's Challenges") you will revisit each of the interviews and cut and paste the excerpts ("rocks and gems") that represent each core theme (one file per core theme).

3 - Focus on one theme at a time, work your way through the interviews, glean all the related data for each theme, then move on to the next theme and repeat.

4 - After completing each theme's file, read through the file several times and bold the "gems" that seem to best capture the essence of that theme.

5 - Without deleting the comprehensive "rocks and gems" file for each theme, create an additional file ("cache") for each theme that contains the meaningful gems.

6 - At the conclusion of this step, you will have a gems-file (or "cache") for each core theme. Ideally, the cache should also include "Counterexamples" for depth. 
Table 1 (continued)

Phase Four: Placing the Gems in the Qualitative Research Crown

1 - Read through the larger file (including "rocks" and "gems") for the first core, emergent theme several times asking yourself:

a) What is the meaning of this?

b) What whys, hows, and processes are taking place within and across gems?

c) Are there any recurring patterns?

2 - Read through the compressed cache (the smaller file including only gems) for each core, emergent theme, again asking yourself the questions in Step 1.

3 - Begin to arrange the gems in a way that sequentially or conceptually presents an authentic, valid, and coherent composite array of gems for each theme.

4 - Repeat the above steps of ordering and arranging gems for each theme until you have your composite array of gems for each of the core themes.

5 - "Cut" (trim/edit) the individual gems while preserving the participant's meaning.

6 - Now that you an array of gems for each of the core themes, consider the themes in an integrated way and ask:

a) Do the themes interact or relate? If so, how?

b) In what order should you present them? What kinds of transitional phrases/ideas seem to lead from one theme to the next in a way that flows?

c) Do the themes work together to tell an important composite story of the individuals and/or families you interviewed that seems true to their experience?

7 - After many drafts, it will be time to face Reviewers A, B, and C. Good luck!

Healthy Aging Study (LHAS), a multidisciplinary collaboration involving researchers from the LSU Health Sciences Center, Tulane School of Medicine, and the University of Alabama at Birmingham. The aims of the project were ambitious and plural but included the desire to capture (quantitatively and qualitatively) the psychological coping of adults across the lifespan in the wake of one of the worst natural disasters in U.S. history - a disaster that had occurred just over an hour's drive from our academic home of LSU in Baton Rouge, New Orleans' sister city. Baton Rouge became a refuge for many of those displaced by the horrors of Katrina ${ }^{5}$ - an event that seemed to animate both the nobler and more predatory elements of humankind. Katie wanted to document these phenomena with more than numbers, she wanted to capture the lived experiences and deeper stories of those directly and indirectly impacted and asked for my assistance in doing so.

Katie's invitation invoked excitement... and trepidation. I was aware that capturing 70+ individuals' Katrina experiences in transcribed form was one thing; getting those stories past journal editors, Reviewer C-types, not to mention Reviewer B-types, and into print was quite another. In my estimation, publishing Katrina-related qualitative data would become increasingly difficult as time passed and as the fascination with, and novelty of, Katrina/Rita cooled and waned - although the present special issue of Current Psychology 10 years later proves me wrong. At that time, I was convinced that if we were going to tackle this project, it needed to be designed and executed in a way that would endure across time - the aim must be more potent and lasting than an ephemeral human interest piece or two. The questions, the interviewing, the transcription processes, the coding and analyses all needed

\footnotetext{
$\overline{5}$ After Katrina hit, my wife met a displaced couple whose vehicle was almost out of gas (indeed, most area gas stations were out of supply for several days). All Baton Rouge hotels were filled, so they lived with us for a while. Such experiences were not uncommon during the weeks following Katrina/Rita.
}

to be sound and rigorous. Within a context of limited infrastructure (i.e., LSU Health Sciences Center and Tulane University School of Medicine had catastrophic damage due to Katrina-related flooding) and a sense of urgency that seemed to be productively channeled...I agreed to join the LHAS team's qualitative research effort.

\section{Criticism of "Monk/Nun in a Cell" Qualitative Research}

One leading criticism of much qualitative work is the pronounced subjectivity (and alleged lack of objectivity) inherent in any project where a solitary individual:

1. Reviews the literature, develops the questions, and determines the sample;

2. Conducts the interviews, does the transcriptions, and performs the coding;

3. Compiles the themes and determines what data to present (or not present); and

4. Tells the composite story of the sample (that he/she selected).

This approach (see Table 1), often employed by graduate students writing qualitative dissertations, is a solo show with several potential flaws. I refer to this as the "monk/nun in a cell" approach because after the interviewing portion of Phase 2, the researcher disappears into her cell to complete Steps 2, 3, and 4 unobserved - emerging months or even years later with a dissertation. It was my employment of this type of design that evoked the criticism of Reviewer B. ${ }^{6}$ By its very nature, the

\footnotetext{
${ }^{6}$ The solo-produced "monk/nun in a cell" design is perhaps necessary for dissertation purposes because multi-authored dissertations are not permitted, but after earning a terminal degree there are alternative and far more efficient, effective, and rigorous qualitative courses to pursue.
} 
"monk/nun in a cell" approach to qualitative inquiry is isolationist and idiosyncratic. Further, it leaves the author with his or her biases unchecked by others during most phases of the project. As noted elsewhere:

Indeed, if it is true that "we see what we seek," an extension of that truism is that we tend to ignore what we do not want to see.... This is a pronounced cost of soloauthored work. There is no...team of co-authors to perpetually say things like, "[T]here is a semi-truck in your blind spot." Nor is there anyone there to hear me figuratively respond in my weaker moments, "What truck? I don't see it and I am certainly not going to write about it" (Marks 2012, pp. 784-785).

Given the vulnerabilities to blind spots and biases inherent in a solo approach, I felt the best approach we could develop for the LHAS hurricane assessment was a variation on a teambased approach my colleague Dave Dollahite and I had begun to develop and employ (Dollahite and Marks 2004). In applying this method, we seek to acknowledge and address the core question raised by "Reviewer B," as explained next.

\section{The Four-Phase, Team-Based (or Quad-Squad) Approach to Qualitative Research}

The core query raised by "Reviewer B" in the review of my soloauthored work was: "Is your research method 'science' and if so, why? " In lieu of leaping into a philosophy of science discussion (i.e., Kuhn 1970/1996), we will focus here on the scientific issue raised by Reviewer B, replicability/reliability. He posited:

There are certainly many ways of knowing; scientific knowing is only one of them. But what defines [scientific knowing]...is the employment of a replicable method of inquiry which thereby allows others to seek to replicate findings reported to ensure that they are indeed reliable.

Four phases of a more "replicable method of inquiry" are discussed next, respectively.

\section{Phase 1: Developing the Interview Protocol and Defining the Sample}

The steps of Phase 1 are outlined in Table 1 but I will focus here on: (a) the pre-project step of Building a Diverse Qualitative Research team - and the culminating Phase 1 steps of (b) Developing the Questionnaire, and (c) Defining the Sample.

\section{Building a Diverse Qualitative Research Team}

The step to build a qualitative research team should be taken as near the commencement of the project as possible because biases play into the formulation of the qualitative interview questions that will be developed (Daly 2008; Slife and Williams 1995). The primary investigator typically has a preexisting, overarching research question in mind. For the LHAS, this question was: "How have individuals coped with the immediate and long-term aftermath of Hurricanes Katrina and Rita?" From this starting point, however, different biases can point the research project in different directions. ${ }^{7}$ Intentionally assembling a diverse group of team members can heighten our awareness of blind spots (thereby minimizing them). In our experience, it can be valuable to have teambased diversity in terms of traditional markers including race/ethnicity, SES/class/background, and gender ${ }^{8}$ - but it is essential to consider specific, project-relevant types of diversity. ${ }^{9}$ More specifically, for the LHAS research team, we ideally wanted some team members who were directly affected by Hurricanes Katrina and Rita as well as some who were only indirectly affected — or relatively unaffected. Including team members with a diversity of project-relevant life experience theoretically heightens our sensitivity to diversity of experience in the participants' lives (Daly 2008). ${ }^{10}$

${ }^{7}$ Examples of LHAS research project choices included:

1. Should the sensitive subject of religion be addressed? (Response: We chose to ask questions regarding spiritual beliefs, religious practices, and faith communities.)

2. Should we focus on positive or negative coping? (Response: We chose to address both, but focused on positive coping.)

3. Whom should we interview? Where should we interview them? How should we interview them? (Responses: We chose to interview women and men from across the adult lifespan. We chose to interview them in their homes, whenever possible. We constructed a semistructured interview protocol that was followed but allowed for participants' narratives to emerge as well.)

${ }^{8}$ Our research teams have been built largely through "skimming the cream" (recruiting outstanding undergraduate students, particularly those who are considering graduate school). This facilitates a win-win where the primary investigator receives valuable assistance, and the undergraduates receive course credit and co-authorship on conference presentations and perhaps even publications.

${ }^{9}$ For example, in team-based qualitative studies on marriage, projectrelevant diversity may incline the primary investigator to include team members from a variety of families of origin (e.g., marital, nonmarital, divorced, step-families, etc.), as well as members from a variety of present relational contexts (e.g., single, married, divorced). This type of sensitivity to project-relevant diversity can strengthen research.

${ }^{10}$ This sensitivity to insider/outsider status is often called the emic/etic consideration (Daly 2008). Another relevant marker of team-based diversity for many studies, including the LHAS project, is a researcher's geographic origin. Our team included the following relevant variations and contrasts, moving from localized to global: (a) New Orleans natives... contrasted with others; (b) Louisiana natives and Southerners... contrasted with Northern transplants (e.g., Illinois, Oregon, Pennsylvania, Utah); and (c) U.S. natives...contrasted with immigrants or internationals (e.g., China, Germany). Each of these important distinctions in origin colored researchers' sensitivity and their interpretation of data. Additionally, although our team primarily hailed from psychology, we also included team members from communication disorders, family studies, social work, history, and law to promote an inter-disciplinary approach. 
A core purpose of building a qualitative research team with varied blind spots and biases is that being sensitive to potentially influential aspects of diversity ${ }^{11}$ can facilitate more rich, insightful, and varied acquisition and interpretation of qualitative data. While building a diverse research team does not ensure a replicable study, the teambased approach does move the project away from some idiosyncratic "monk/nun in a cell" limitations and towards checking and balancing blind spots and biases - biases that are influential at least as early as questionnaire development, briefly addressed next.

\section{Developing the Qualitative Interview Questionnaire}

An early and salient issue that arises is: What questions are most important to ask participants? If we were composing a 200 -item questionnaire for a survey-based quantitative project, instrument development would be of critical importance (Trochim and Donnelly 2008). By comparison, if (as in the qualitative portion of the LHAS hurricane assessment) only seven questions are to be asked - and each of those questions will require $6-8 \mathrm{~h}$ of transcription time for every hour of participant responses... and a similar additional investment of time for coding and analysis, then the stakes for getting the questions "right" are considerably higher (Patton 2002). Elsewhere, this comparison of developing the questions for a qualitative project has been compared with selecting a specific surface location for drilling a mineshaft (Marks and Dollahite 2011). Quantitative survey work is a lower risk proposition due to the breadth and scope that can be covered-although most of the results will likely lack in explanatory depth. The qualitative exercise of "mining the meanings" is often a highrisk, low-reward venture because even when "gems" are found, they are often not in the more readily accepted quantitative currency of the field. Lucid, clear, stimulating questions are essential to give your qualitative project a chance to crack the publication barrier.

As indicated in the Quad-Squad Method (Table 1), it is wise to seek scrutiny of the questions from various peers and laypersons at one or two different points during early development (i.e., Phase 1: Steps 5 and 7) because questions that seem promising in the ivory tower can fall flat in the participants' real-world homes. In sum, with instrument design it is wise to invoke the best efforts of your forwardthinking team (and other persons who are willing to give candid feedback) in deciding what questions will provide you with the most effective "mining tool" (Marks and Dollahite 2011). When you are confident in your mining tool (interview questionnaire) you still have to decide on your drilling commencement spot, discussed next.

\footnotetext{
${ }^{11}$ Again, this may be particularly true with experiences that relate directly to the project, such as (in our LHAS project) including team members who were New Orleans natives that experienced Katrina.
}

\section{Defining the Sample}

With the mining tool in hand, the next pressing question is: "Where do we drill?" Phrased differently, whom do we sample? Here the Quad-Squad approach employs a dramatically different technique than most quantitative work. In quantitative work, the gold standard is a representative, generalizable sample (Trochim and Donnelly 2008). In such work, we are also likely to be concerned with central tendencies in the data (e.g., means, medians) and variations on these middle points (i.e., standard deviations) (Salkind 2004). In quantitative research, it is rare to devote much attention to outliers or "aberrations" at the outer edges of the bell curve - indeed it is not uncommon to delete statistical outliers altogether (Neuman 1997).

A shift in perspective is needed to optimally perform theoretical or purposive sampling for a qualitative study (Daly 2008). Remember that generalizability is not the aim of most qualitative work. We surrender that ideal from the outset because generalizability is not remotely attainable with small samples - and most qualitative studies have samples of less than 100 - indeed, many "monk/nun in a cell" dissertations have samples of less than 20 .

As a representative, generalizable sample vanishes from possibility, so does our focal concern with the "average" individual represented by the mountainous center of the bell curve. As we turn our attention away from the typical concerns of central tendencies and toward what our study's unique contribution will be, we must consider: "What life experiences or qualities are most likely to characterize participants who will give us the richest, deepest, and most meaningful data on the research topic of concern?" Let's use the following as a sample research topic test case: "How does religious belief influence personal decision making?" William James (1902/1997) explains:

We may learn most about a thing when we view it...in its most exaggerated form. This is as true of religious phenomena as of any other kind of fact. The only cases likely to be profitable enough to repay our attention will therefore be the cases where the religious spirit is unmistakable.... Its fainter manifestations we may tranquilly pass by (p. 48).

The promise of potential gems does not glitter in the center but in the remarkable and "unmistakable" expressions on the edges. In the preceding example, the sample most likely to offer us gems regarding "how religious beliefs influence decisions" will not be the "fainter" or religiously lukewarm center but those passionately faithful individuals whose "religious spirit is unmistakable." Following the lead of William James and (nearly a century later) leading family stress researcher and practitioner Pauline Boss (1999, 2002), we have adopted 
a variation on purposive sampling that has been called prototypical sampling ${ }^{12}$ - the intentional selection of ideal and richly promising cases for the phenomenon in question (e.g., Marks et al. 2009; Silva et al. 2009).

Our early work with the LHAS sample was completed in 2006 and related qualitative papers were subsequently published (Cherry 2009; Silva et al. 2009; Tausch et al. 2011). In 2009 , we wondered about the fate of those who lost homes in the floodwaters of Katrina. We wanted to learn: "How have individuals coped with the immediate and long-term aftermath of Hurricanes Katrina and Rita?" It was determined that a richly promising population to "mine" would include those from the devastated coastal parishes of south Louisiana, including areas in St. Bernard and Plaquemines Parishes where homes were not only damaged but leveled - and, in some cases, quite literally gone. The interviews with these sampled participants did indeed provide many gems and insights (e.g., Cherry 2015). For comparison purposes, other interviews were conducted with participants who were less profoundly or indirectly affected but those interviews offered relatively little. An additional note is that we conducted further research in wake of the British Petroleum Deepwater Horizon Oil Spill in 2010 (Lyon et al. 2015). Again, using a prototypical approach to sampling, we determined to interview those who were most poignantly influenced by the disaster...those who made their living on the waters of the Gulf via the shrimp, fishing, and oyster trades. As with the Katrina/Rita waves, the most valuable data came from those who were most affected.

In the discussion of Phase 1, I have recommended three important steps: (1) the "pre-project" step of Building a Diverse Qualitative Research Team (with varied blind spots and biases); (2) Developing the Questionnaire, and (3) Defining the Sample (a purposive, prototypical sample). To offer a minimalist version of all that has been emphasized in Phase 1, let me summarize: We must be asking meaningful questions to those who can best offer meaningful answers. Based on costly errors and experience, I warn that if an individual or team fails to successfully execute this charge, the rest of the research project is liable to become a laborious and unsuccessful attempt to turn straw into gold. If, however, meaningful questions are asked to persons with meaningful insights in Phase 1, the noteworthy challenge of Phase 2 may become scientifically and systemically managing the wealth of gems that your mining will reveal. ${ }^{13} \mathrm{It}$ is to Phase 2 of the Quad-Squad approach that we now turn.

\footnotetext{
$\overline{12}$ Boss applied a prototypical sampling approach in developing her widely used concept of ambiguous loss by purposively sampling individuals and families who had experienced dramatic episodes of ambiguous loss, including families with POW/MIA fathers/sons, families with abducted children, and families caring for a member with Alzheimer's Disease. In each of these cases, powerful manifestations were intentionally selected and sampled.

${ }^{13}$ As one might assume, we have had a wide variation of data quality with the LHAS. Some questions and participants have yielded much in the way of gems, others have yielded very little.
}

\section{Phase Two: Data Collection and Analysis}

The scientific criticisms of Reviewer B focused on problems with replicability and/or reliability. These criticisms were vital to address in the LHAS, but another fundamental scientific concern is whether research is valid. For Phase 2, a related question is: How can you best ensure that your participants are telling "the truth"? ${ }^{14}$ Previous work counsels researchers to consider the impact and influence of factors such as the match between interviewer/participant gender and race (Denzin and Lincoln 2000). Such consideration is wise, but based on experience the single most important factor is whether the interviewer is a person the participants will trust with their truth. The interviewer needs to possess a combination of earnestness, authenticity, trustworthiness, and humanity that will elicit both truth and depth from the participant. Ideally, the participant will invite the interviewer to step onto her personal, "sacred ground" (Marks 2004). An essential addition to the Phase 1 charge to "ask meaningful questions to persons best equipped to provide meaningful answers" is that the questions must be asked by the right person - a person who will elicit truth, depth, and meaning. In the case of our 5 year post-Katrina study, the primary investigator (a skilled interviewer possessing the qualities outlined previously) took this seriously and went to the staggering effort of personally interviewing nearly two-thirds $(65 \%)$ of the participants in their own homes (an hour or two from LSU). The total number of hours required to do so, including extensive travel time and arrangements, approached 1,000 (over the two and a half years of data collection in the coastal parishes of south Louisiana). This figure does not include transcription time (or double-checks of the transcriptions), ${ }^{15}$ nor does it include coding. Coding is overviewed next.

\section{Some Notes on Qualitative Coding}

After a transcription is completed (and in our case, doublechecked through an audio-visual data audit), coding begins.

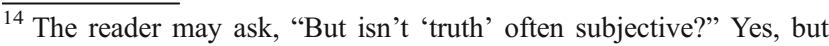
whether we are pursuing more concrete, objective truths and facts such as "How many times did you attend church last month?" (a question that U.S. participants often overreport/lie about; see Hadaway et al. 1998) — or whether we are asking a more subjective question such as "How have you coped with Hurricane Katrina?" our study's validity depends in large degree on the objective truthfulness and accuracy of participants' reports.

${ }^{15}$ As briefly mentioned in Phase 1, experienced qualitative researchers estimate $6-8 \mathrm{~h}$ of transcription time for every hour of participant responses. In the LHAS, after transcriptions are completed by one team member, a second team member conducts an audio-visual data audit/ double-check by listening to the audio interview while carefully following the typed transcription to check for errors. (Please see Phase 2: Step 5 for an additional note of importance relating to transcription in solo projects.)
} 
We coded the first interviews as soon as possible after they were conducted, transcribed, and audited. It is neither necessary nor prudent to wait until all data collection and transcriptions are completed before commencing coding-indeed, working in that manner can delay your project by several months. In the team-based, Quad-Squad model we use in the LHAS, interviewing, transcriptions, data audits/double checks, coding/analysis, and other steps are often occurring simultaneously, with some team members carrying out multiple tasks.

The first coding step (whether doing solo work or team-based work) is open coding (for details, see Strauss and Corbin 1998). In simple terms, open coding involves the coder reading through an interview and recording (typically in the blank left margin of the hard copy) a brief conceptual "code" that reflects what the participant is discussing. ${ }^{16}$ Our flexible guideline is about one code per vertical inch of interview text.

In the LHAS hurricane assessment and later work in the coastal parishes, each interview is independently open coded by two members of a coding partnership. After independently coding an interview, the two-person coding partnership meets together "to discuss, compare, and contrast our independent open coding from the previous week on a line-by-line, page-by-page basis, with each member alternatively 'leading out' by discussing her/his personal open coding of a given page" (Marks et al. 2009, p. 200). If Partner A leads out on page 1, then Partner B leads out on page 2, alternating through the interview, and discussing similarities and differences in their coding as they go. Relative consensus is sought, with more value being placed on open codes that were repeatedly identified by both partners. Recurring emergent codes are identified through Numeric Content Analysis (NCA), as follows (Phase 2: Steps 7-9). After the check-and-balance of meeting and discussing open codes with the coding partner, some adjustments may be made (e.g., some missed codes might be added, some that were a "stretch" might be deleted). Next, each coder performs a Numeric Content Analysis of their (adjusted) open coding for each interview, providing a "data accounting sheet" (Miles and Huberman 1994, p. 80) that lists all codes identified in a given interview, as well as the frequency (e.g., was "family as a coping resource" mentioned one time or twelve?). For convenience, our team members use a separate Post-It note for each interview's NCA. Researchers' Numeric Content Analysis (NCA) for each coded interview are recorded and copied, offering at least two "at-a-glance"

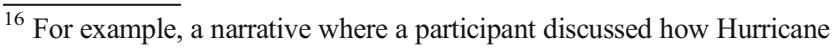
Katrina irretrievably changed some aspects of life is labeled by a team member with the open code "old 'normal' is gone forever."
}

perspectives of the concepts/themes in each interview. ${ }^{17}$ Eight total coders (i.e., two teams of two, two-person partnerships) are recommended. ${ }^{18}$ All team members' NCAs are considered-the team-based, Quad-Squad method is democratic and tempers the idiosyncrasies of any single member. This is a vital feature of the method when the reader recalls that a pronounced criticism of the solo-authored work reviewed by Reviewer B was:

To me, the core question becomes, what makes this work distinct from journalism? Until that can be answered to my satisfaction, I prefer to gather information of the kind presented in this paper in newspapers and magazines, where the journalism is transparent.

The team-based, Quad-Squad approach, with its systematic NCA-based presentation, moves research a discernible qualitative and quantitative step or two away from a journalist who is relatively free to cherry pick sound bites, whether or not they are representative. Bona fide core, emergent themes from the interviews are identified based on demonstrated prevalence ${ }^{19}$ not only within interviews but across interviews. For example, "prayer as a coping resource" was coded half a dozen times in some LHAS interviews but it would not be designated as a core, emergent theme unless it also recurred in a majority of the interviews. Systematic accounting of codes (e.g., total number of codes and total number of interviews where the code occurred) will be perceived as unappealing and even offensive "bean counting" to some qualitative researchers, but remember that our focal aim is to build and demonstrate methodological rigor that may be appreciated by Reviewers B and $\mathrm{C}$ - and most journal gatekeepers.

Space does not permit detailed discussion of Phase 2: Steps 8-18 (Table 1) but the deeper into the coding the team gets, the more confidence and data-based evidence you will have regarding the core, emergent themes. Our experience over the years with the LHAS qualitative data has been that by the conclusion of coding, consensus is typically achieved around a small number of themes (typically 4-6).

\footnotetext{
${ }^{17}$ In the most recent work on the LHAS, eight coders were employed (i.e., four coding partnerships). By attacking the coding in roughly 32 interview clusters, this meant that each team would be coding and jointly reviewing eight interviews per semester.

${ }^{18}$ We have typically used eight coders, divided into two teams of four, where each team is coding one group in a comparative study (e.g., one team codes the "under 65 years" group and the other team codes the "65 and over" group). However, if there is no age-graded (or other) comparison in your study, four coders will suffice.

${ }^{19}$ Salience is also considered. Sometimes a concept is mentioned only once in an interview, but is of profound importance. However, the concept must recur across several interviews to warrant consideration as a core, emergent theme.
} 
Referencing Reviewer B's call for replicable and reliable work, we present core themes that: (a) all individual coders repeatedly identify across interviews, (b) that all coding pairs identify with consensus, and (c) that both coding teams (4-8 coders each) identify with consensus. For the LHAS, we present only themes that achieved consensus at all levels. Less prevalent themes and concepts may be sprinkled in as seasoning, but these are not designated with the carefully reserved appellation of core theme. With core themes grounded in qualitative and quantitative evidence, we move to Phase 3.

\section{Phase Three: Caching the Rocks and Gems for Core Themes}

The systematic compilation of Numeric Content Analyses from team-based coding efforts is a necessary but not sufficient effort to optimizing the rigor and inter-rater reliability of a qualitative project. The next phase we employ in the QuadSquad approach involves a return to the mining metaphor of finding and featuring the gems your participants have offered the research team.

Having identified the core, emergent themes in the data, team members revisit the interviews and locate the data excerpts that were open coded in connection with the core, emergent themes. These supporting excerpts are then electronically copied and pasted (with corresponding interview number and page number) into data files - with a separate file for each core theme. The result is that each core, emergent theme has several pages of supporting data-consistent with Patton's (2002) suggestion of creating a careful, data "audit trail" (p. 93). Many of these data excerpts will be rather mundane and ordinary "rocks" that merely substantiate the core theme without illuminating it or adding vibrant color. However, during this caching of relevant, theme-supportive rocks, coders also highlight ${ }^{20}$ gems. Webster's Dictionary refers to a gem as something "precious" or "prized for great beauty." Qualitative gems are prized quotes, excerpts, or narratives that add a depth, transparency, insight, or color to the discussion and presentation of a core theme. As previously hinted, gems are most likely to be discovered when meaningful questions are asked by a skilled, authentic interviewer to a relevantly experienced person who is well-equipped to deliver a meaningful answer. An invaluable addition to this formula to enhance the discovery of gems is to repeatedly ask the participant for personal, real-life stories that illustrate the concepts that are being examined. Hardy (1968) has observed that: "We dream in narrative, daydream in narrative, remember, anticipate, hope, despair, believe, doubt, plan, revise, criticize, construct, gossip, learn, hate, and love by narrative" (p. 5; cf. Marks et al. 2012, p. 188). Because, as humans, we are immersed in

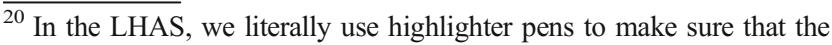
gems are noticed and filed.
}

narrative, we tend to best communicate through the telling of story - particularly our own (Myerhoff 1980). Accordingly, many of the richer available qualitative studies employ some variation of a narrative approach (Josselson and Lieblich 1993), described below:

On a basic level, the narrative approach encourages the participant to relate real-life experiences (personal narratives) as illustrations of constructed meanings or beliefs.... Through narratives, personal and shared family meanings and experiences stretch backward and forward in time, thereby offering a fluid motion picture of process (Marks and Dollahite 2011, p. 183).

To maximize your mining success, make sure that you have story-seeking tools in your questionnaire. The result will likely be fewer rocks and more gems.

At the conclusion of Phase 3, we have comprehensive files containing all of the rocks and gems for each core theme ${ }^{21}$ - and special caches reserved for the finer and more colorful gems. ${ }^{22}$ However, even the most precious gems typically need some cutting, contrasting, and artful juxtaposition to best convey their inherent color and quality. This point brings us to the final phase-placing the gems in the qualitative research crown.

\section{Phase Four: Placing the Gems in the Qualitative Research Crown}

As we move into the Phase 4 task of representing the core findings via placing the gems in the qualitative research crown, we may question, "Are we now 'doing' art or science?" The best qualitative research tends to involve aspects of both. ${ }^{23}$

In Phase 4, the coder (or team of coders) reads through both the larger files (comprised of rocks and gems) and the smaller caches (of gems only) to look for deeper meanings behind the recurring themes - including "Whys, Hows, and Processes." For example, one recurring coping strategy the LHAS team

\footnotetext{
${ }^{21}$ There are qualitative software packages that can be efficient and helpful in performing the type of work outlined in Phases 1, 2, and 3. Such software can also be helpful in managing larger qualitative data sets. However, even the best available software cannot perform in-depth and nuanced coding.

${ }^{22}$ Like great literature, rigorous and valid qualitative research should capture complexities and tensions inherent in the human condition (Coles 1990). Accordingly, the data cache should include some "counterexamples" of core themes as well. For example, in our recent work we have discussed not only how faith communities reportedly served as a profound support (in many instances) but also that when a faith community or congregation to which an individual or family is closely tied lets them down or fails them "it [is] both disappointing and hurtful in ways that ... elicit deeper frustration and pain than failures by secular agencies and institutions" (cf. Marks et al. 2015; Marks and Dollahite 2001, p. 636).

${ }^{23}$ Daly (2008) has noted that "In both art and science, representation is the symbolic means by which we portray aspects of reality" (p. 16).
} 
noted in the participants' interviews after Katrina hit was "Helping Others," but most of the "rocks" offered little insight into why and how helping others mattered as they coped with profound loss. Some LHAS gems, however, offered explanations like these:

[A]fter the storms.... helping [other] people, that [is what helped me to cope.... I took on so much other stuff helping other people [that] it kind of drowned out what I was going through and God fixed it. So while I was trying to fix somebody else['s situation], God was fixing mine. I...just continued to stay in prayer and helped those that needed help [and in the process, God helped me]" (Silva et al. 2009, pp. 236-237).

Two of this participant's experienced truths were that "helping other people...drowned out what I was going through" and that while she was caring for the problems of others that "God was fixing mine." This gem, like many, required some careful cutting to eliminate extraneous matter, while preserving the meaning and intent of the participant. $^{24}$

As the gems are selected and cut for their placement in the crowning findings section of the manuscript, an additional struggle of how to position and order the selected gems arises. $^{25}$ If Phases 1-3 have gone well, a pronounced challenge is the pain of cutting many gems you wish to include. One of my qualitative research mentors, the late Tamara Hareven, referred to this as "chopping off your own right arm." Even so, you will typically need to select (for a four theme paper) no more than a single-spaced page or two of representative gems per theme. ${ }^{26}$ As the within-theme order of gems settles into place, ${ }^{27}$ two additional decisions face the team: (1) In what order do we present the four (or so) themes;

\footnotetext{
${ }^{24}$ Another gems-related issue during Phase 4 is that qualitative gems vary widely in size but tend to come in clusters. Some participants' interviews seem almost void of gems, while others provide a mother lode. As a result, there may be a temptation to rely inordinately on a handful of particularly gem-laden interviews. This temptation should be resisted or the team may fall guilty of Reviewer B's charge that we are doing warmed-over "journalism," not science.

${ }^{25}$ In the LHAS, about 70 total participants were interviewed. At an average of 25 double-spaced pages of transcript per participant interview, we were facing the challenge of coding/analyzing an estimated 1,750 pages of qualitative data. The larger "rocks and gems" files for the core themes were often 10 pages or longer per theme (multiplied by four to six themes). In a final article or chapter, a maximum of about four singlespaced pages of gems (total, for all themes) will be presented.

${ }^{26}$ A related challenge is: Do we include (for example) three or four longer narratives or a dozen shorter excerpts? Our choices in the LHAS have varied - a combination of longer and shorter gems may be ideal.

${ }^{27}$ After the painful winnowing process, it has proven helpful for us to print hard copies of the remaining gems (like individual puzzle pieces) and to test various orderings of the gems for flow and cohesiveness. There are often stories within the story of each theme that can be told more effectively and fluidly through carefully ordering of the selected gems.
}

and (2) In terms of qualitative data presentation, are you a "diva soloist" or a "choir director"?

A Note on Ordering the Themes If the reader will pardon the mixing of metaphors, we will shift from the metaphors of mining, gems, and crowns to (of all things) a $4 \times 100 \mathrm{~m}$ relay team. Most of the qualitative LHAS publications and our more recent work contain four themes (plus or minus one). If each theme is a compared with a "leg" of the four-theme relay team, you may consider having your best "starter" as Theme 1-a theme that is quickly engaging to the reader as an interest grabber. Themes 2 and 3 are ordered with sensitivity to "handoffs" or transitions (e.g., if Theme X follows Theme 1 more smoothly than Theme Y, then Theme X becomes Theme 2 and Theme Y becomes Theme 3). Your last theme, Theme 4, is your "anchor" leg. Simply put, you save the best for last. With all themes and gems in place (but subject to adjustment) we move to the next issue.

In Qualitative Terms, are you a Diva Soloist or a Choir Director? To continue with mixed metaphors, we now switch to a comparison of qualitative data presentation with choral music. The author(s) must determine how much of the findings section will be comprised of participant-voiced data... and how much will be author-driven commentary and/or summary. Will you be a choir director who blends and harmonizes voices or will you be unable to resist the temptation to grab the microphone for repeated diva solos? We wrote in one LHAS study (Marks et al. 2009) and in recent work, "Our primary aim is to present our participants' voices and to convey their experiences and observations with as much fidelity as possible. In keeping with this goal, our interpretation and explanations are brief" (Marks et al. 2015). Here, we have a prodirector/anti-diva bias, but a balance is needed. If your team has been systematically coding qualitative data for weeks, months, or years, there will be some researcher-identified connections and insights that need to be highlighted. The synergistic principle that the whole is greater than the sum of the parts is true not only for the research team, but for data analysis as well. In terms of intellectual effort, this is often the most strenuous and most enjoyable and meaningful portion of the Quad-Squad method. It is, both metaphorically and literally, the crowning work of the project. Our approach here has been to have extensive team-based discussion about themes and content, but to designate a point person who leads out on the authorship for each manuscript - followed by careful revision work by multiple team members. ${ }^{28}$ After many drafts, it will be time to submit the manuscript and to face Reviewers A, B, and C.

\footnotetext{
${ }^{28}$ In the LHAS, several different graduate students and a few undergraduate students have served as the "point person"/first author for presentations and manuscripts.
} 


\section{Conclusion}

As we wind down this tour of the Quad-Squad coding approach, ${ }^{29}$ I note that Denzin and Lincoln's (2000) Handbook of Qualitative Research includes more than 40 chapters from an array of authors, many of whom apply methods that differ from the Quad-Squad Approach. There are many ways of doing qualitative work - the presented approach has proven pragmatic and productive for our teams and me. ${ }^{30}$ However, the Quad-Squad method is not a silver bullet. To my knowledge, in roughly 100 attempts, we have yet to thoroughly win over a single "Reviewer B." Further, in spite of the Quad-Squad methodology which is both methodologically and pragmatically superior to my early "monk/nun in a cell" efforts, our research teams (including the LHAS teams telling compelling stories of Hurricane Katrina) have enjoyed only mixed success with ambivalent "Reviewer C" types and editors. In sum, the development and application of this positivist-sensitive and Reviewer $B$-influenced method has increased the acceptance rate of my qualitative submissions from about $33 \%$ (with solo "monk in a cell" work in my early career) to about $50 \%$ (with the Quad-Squad Method) - a marked improvement, but far from a panacea. Although I do not expect to convert Reviewer $\mathrm{B}$, he retains a front-row seat in the audience to which we write. I respect him and am indebted to him - for he has pushed me to work smarter and to do better science, even if our personal visions of science vary.

I highly value thoughtfully and rigorously executed quantitative research and believe that there is something uniquely salient about gold-standard, representative, replicable research that captures and conveys an informative big picture. However, I also believe that when a skilled, authentic, and trustworthy interviewer asks meaningful qualitative questions to a person who has experienced particular life events that especially qualify her to offer insight and reflection, that this process may offer a type of validity or depth of truth that is difficult access in other ways. Further, if some "truths" shared by experienced participants are sufficiently clarion that the systematic coding efforts of four diverse team members reveal those "truths" with uniform consensus, and another team of four diverse team members identifies the same "truths" or themes with uniform consensus, then perhaps we have pushed past journalism and moved a step or two in the direction of the classical research of ideals of validity and reliability.

\footnotetext{
${ }^{29}$ I note that the foundation for this approach was established in a previous decade of largely solo (i.e., "monk in a cell") work under the guidance of three qualitative scholars to whom I owe debts that cannot be repaid; Dave Dollahite, Rob Palkovitz, and the late Tamara Hareven. Many of the better ideas in the Quad-Squad Method are borrowed or adapted from them.

${ }^{30}$ Our LHAS team has produced ten qualitative manuscripts, counting "in press" work.
}

Trying to capture "truth" or validity and to do so with reliability in any qualitative research project is a daunting task. Trying to capture the truths from the diverse array of painfilled, hope-tinged, and resilience-revealing stories behind Hurricane Katrina's immediate aftermath and over the years since the storm (Cherry 2015; Marks et al. 2015) has been especially challenging... but also humbling and life enriching. As researchers and as human beings we learned much from the often remarkable participants who allowed us to step on to their personal sacred ground.

As we submit our qualitative work, reviewers continue to point out methodological flaws in the Quad-Squad method. Some flaws seem to be issues of reviewer preference, but other criticisms seem substantive and valid. We resonate with the qualitative master scholar Kerry Daly (2008) who confesses in the preface of one of the finest books on qualitative research, "Even though I have been practicing and teaching qualitative research for more than 20 years, I still struggle with whether I am doing it right" (p. xi).

Do flaws remain in the Quad-Squad approach to qualitative research? Certainly. Did we always do it "right"? No, we made many mistakes. Have we completely converted or convinced Reviewer B or any member of his cadre? Probably not... as I mentioned we seem to be roughly zero for 100 to date. What I can say with conviction, however, is that our diverse qualitative research teams performed the monumental task of capturing participants' stories and truths behind surviving Hurricanes Katrina and Rita in substantively more valid, reliable, replicable, and rigorous ways than Katie Cherry and myself could have on our own. This is the Quad-Squad truth behind our best efforts to capture the truths from coping with Katrina.

\section{References}

Ambert, A., Adler, P. A., Adler, P., \& Detzner, D. F. (1995). Understanding and evaluating qualitative research. Journal of Marriage and Family, 57, 879-893.

Boss, P. (1999). Ambiguous loss. Cambridge: Harvard University Press. Boss, P. (2002). Family stress management. Thousand Oaks: Sage.

Cherry, K. E. (Ed.). (2009). Lifespan perspectives on natural disasters: Coping with Katrina, Rita, and other storms. New York: Springer.

Cherry, K. E. (Ed.). (2015). Traumatic stress and long-term recovery: Coping with disasters and other negative life events. New York: Springer.

Coles, R. (1990). The call of stories. Boston: Houghton Mifflin.

Daly, K. (2008). Qualitative methods for family studies and human development. Thousand Oaks: Sage.

Denzin, N. K., \& Lincoln, Y. S. (Eds.). (2000). Handbook of qualitative research. Thousand Oaks: Sage.

Dollahite, D. C., \& Marks, L. D. (2004). A qualitative test of a conceptual model of how highly religious families strive to fulfill sacred purposes. Paper presented at the TCRM Workshop of the National Council on Family Relations, Orlando, FL. 
Hadaway, C. K., Marler, P. L., \& Chaves, M. (1998). Overreporting church attendance in America. American Sociological Review, 63, 122-130.

Hardy, B. (1968). Towards a poetics of fiction: an approach through narrative. Novel, 2, 5-14.

James, W. (1902/1997). The varieties of religious experience. New York: Touchstone.

Josselson, R., \& Lieblich, A. (1993). The narrative study of lives. Newbury Park: Sage.

Kuhn, T. (1970/1996). The structure of scientific revolutions. Chicago: Chicago Press.

Lyon, B. A., Nezat, P. F., Marks, L. D., \& Cherry, K. E. (2015). When multiple disasters strike: Louisiana fishers in the aftermath of hurricanes and the British Petroleum Deepwater Horizon oil spill. In K. E. Cherry (Ed.), Traumatic stress and long-term recovery: Coping with disasters and other negative life events. New York: Springer.

Marks, L. D. (2004). Sacred practices in highly religious families: Christian, Jewish, Mormon, and Muslim perspectives. Family Process, 43, 217-231.

Marks, L. (2012). "We see what we seek": responses to the reviews of Amato, Eggebeen, and Osborne. Social Science Research, 41, 784-785.

Marks, L. D., \& Dollahite, D. C. (2001). Religion, relationships, and responsible fathering in Latter-day Saint families of children with special needs. Journal of Social and Personal Relationships, 18, 625-650.

Marks, L. D., \& Dollahite, D. C. (2011). Mining the meanings from psychology of religion's correlation mountain. Journal of Psychology of Religion and Spirituality, 3, 181-193.

Marks, L. D., Cherry, K. E., \& Silva, J. L. (2009). Faith, crisis, coping and meaning making after Katrina: A qualitative, cross-cohort examination. In K. E. Cherry (Ed.), Lifespan perspectives on natural disasters: Coping with Katrina, Rita and other storms (pp. 195-215). New York: Springer.

Marks, L. D., Dollahite, D. C., \& Barker, K. (2012). "Don’t forget home": The importance of sacred ritual in families. In J. Hoffman (Ed.),
Understanding religious rituals (pp. 186-203). New York: Routledge.

Marks, L., Cherry, K., Hatch, T., \& Lu, Y. (2015). Faith-based communities after a disaster: Successes and failures in the wakes of Hurricanes Katrina and Rita. In K. E. Cherry (Ed.), Traumatic stress and long-term recovery: Coping with disasters and other negative life events. New York: Springer.

Miles, M., \& Huberman, A. (1994). Qualitative data analysis. Thousand Oaks: Sage.

Myerhoff, B. (1980). Number our days. New York: Touchstone.

Neuman, W. L. (1997). Social research methods (3rd ed.). Boston: Allyn $\&$ Bacon.

Patton, M. Q. (2002). Qualitative research methods and evaluation practices. Thousand Oaks: Sage.

Salkind, N. J. (2004). Statistics for people who (think they) hate statistics. Thousand Oaks: Sage.

Silva, J. L., Marks, L. D., \& Cherry, K. E. (2009). The psychology behind helping and prosocial behaviors: An examination from intention to action. In K. E. Cherry (Ed.), Lifespan perspectives on natural disasters: Coping with Katrina, Rita and other storms (pp. 219-240). New York: Springer.

Slife, B. D., \& Williams, R. N. (1995). What's behind the research?: Hidden assumptions in the behavioral sciences. Thousand Oaks: Sage.

Strauss, A., \& Corbin, J. (1998). Basics of qualitative research: Techniques and procedures for developing grounded theory. Thousand Oaks: Sage.

Tausch, C., Marks, L. D., Brown, J. S., Cherry, K. E., Frias, T., McWilliams, Z., Melancon, M., \& Sasser, D. (2011). Religion and coping in the aftermath of hurricanes Katrina and Rita: qualitative themes from the Louisiana healthy aging study. Journal of Religion, Spirituality, and Aging, 23, 236-253.

Trochim, W., \& Donnelly, J. P. (2008). The research methods knowledge base (3rd ed.). Mason: Cengage. 